Jurnal Informatika dan Rekayasa Perangkat Lunak (JATIKA)
Vol. 2, No.3, September 2021, page-page. 414 420
ISSN 2723-3367
E-ISSN 2797-3492
available online at:http://jim.teknokrat.ac.id/index.php/informatika

\title{
GAME EDUKASI PUZZLE RUMAH ADAT TRADISIONAL INDONESIA BERBASIS ANDROID
}

\author{
Dyan Yunanto \\ Universitas Teknokrat Indonesia \\ dyan_yunanto@teknokrat.ac.id
}

Published: 30 September 2021

\begin{abstract}
Puzzle games are a way or style in the process of early childhood learning that is more suitable to increase children's learning interest so that the learning process feels more fun, the problem that arises is how to introduce and educate about traditional Indonesian traditional home culture so that the younger generation can get to know and preserve traditional Indonesian culture. To overcome this problem, a game is made that can introduce and educate about traditional Indonesian traditional house culture. While the programming language used in building games is constrcut2. The results of implementation and trials conducted by researchers, it can be concluded that traditional Indonesian traditional house puzzle education games can recognize and educate indonesia's most traditional culture, especially traditional house culture.
\end{abstract}

Keywords: Rumah Adat, Traditional, Indonesian, Puzzle Game.

\begin{abstract}
Abstrak
Game puzzle merupakan cara atau gaya dalam proses pembelajaran anak usia dini yang lebih sesuai untuk meningkatkan minat belajar anak sehingga proses pembelajaran terasa lebih menyenangkan, masalah yang timbul ialah bagaimana cara untuk mengenalkan dan mengedukasi tentang budaya rumah adat tradisional indonesia sehingga generasi muda dapat mengenal dan melestarikan kebudayaan tradisional indonesia. Untuk mengatasi masalah tersebut dibuat sebuah permainan yang dapat mengenalkan dan mengedukasi tentang kebudayaan rumah adat tradisional indonesia. Sedangkan bahasa pemrograman yang dipakai dalam membagun game adalah constrcut2. Hasil implementasi dan ujicoba yang dilakukan oleh peneliti, dapat disimpulkan game edukasi puzzle rumah adat tradisional indonesia dapat mengenalakan dan mengedukasi kebudayaan teradisional indonesia khusunya budaya rumah adat.
\end{abstract}

Kata Kunci: Rumah Adat, Tradisional, Indonesia, Game Puzzle.

\section{To cite this article:}

Dyan Yunanto. (2021). GAME EDUKASI PUZZLE RUMAH ADAT TRADISIONAL INDONESIA BERBASIS ANDROID. Jurnal

Informatika dan Rekayasa Perangkat Lunak, Vol(2) No(3), 414-420.

\section{PENDAHULUAN}

Indonesia sebagai negara kepulauan memiliki adat dan budaya yang berbeda-beda di setiap pulau yang ada di Indonesia. Perbedaan adat dan budaya indonesia menjadikan indonesia sebagai negara yang memiliki kekayaan akan adat dan budaya. Budaya daerah merupakan kekayaan bangsa yang perlu di jaga dan di perhatikan di era globalisasi saat ini. Salah satu bentuk budaya indonesia adalah kearifan lokal. Kearifan lokal dalam sistem budaya di Indonesia tercermin dalam keberagaman agama, keberagaman suku/ etnis, keberagaman bahasa. Kearifan lokal merupakan elemen budaya yang harus digali, dikaji, dan direvitalisasikan karena esensinya begitu penting dalam penguatan fondasi jati diri bangsa dalam menghadapi tantangan globalisasi. Salah satu kekayaan kebudayan indonesia yaitu bentuk rumah adat tradisional.

Rumah adat tradisional di Indonesia sangat beragam dan setiap wilayah di Indonesia memiliki rumah adat yang berbeda-beda. Arsitektur rumah adat merupakan wujud paling nyata dari kebudayaan. Akan tetapi masih 
banyak warga Negara Indonesia yang belum mengetahui rumah-rumah adat yang ada di Indonesia dari anak-anak bahkan orang dewasa. Generasi muda adalah sebagai generasi penerus bangsa dan penerus tradisi budaya Indonesia. Namun, pengaruh budaya asing yang semakin gencar, membuat generasi muda tidak tertarik untuk mempelajari budaya tradisional, bahkan sedikit demi sedikit telah menjauhi dan mulai melupakan budaya tradisional bangsa. Generasi muda Indonesia harus dikenalkan dengan kebudayaan Indonesia sejak dini karena pada masa itu daya ingat bekerja dengan baik dan pada masa itulah seharusnya ditanamkan jiwa nasionalisme agar lebih mencintai dan menghargai kebudayaan Indonesia.

Generasi muda indonesia di usia dini antara umur 3-6 tahun berada dalam masa Golden Periode (Periode Keemasan) perkembangan otak mereka. Dalam usia ini, mereka berada pada masa pertumbuhan dan perkembangan yang paling pesat baik fisik maupun mental. Salah satu cara untuk memperkenalkan kebudayaan rumah adat indonesia melalui sebuah game. Game dapat dimanfaatkan oleh masyarakat dan kaum pendidik sebagai media untuk menyampaikan berbagai jenis pendidikan dan pembelajaran tentang budaya yang menarik dan menyenangkan. Manfaat lain adalah aspek kecerdasan dan reflek saraf yang sebenarnya juga sedikit banyak terasah dalam sebuah game, terutama game yang bersifat kompetitif. Dengan belajar melalui visualisasi yang menarik, diharapkan semangat untuk belajar tentang budaya akan lebih termotivasi.

Salah satu sistem operasi mobile smartphone yang sedang berkembang saat ini adalah sistem operasi Android. Android adalah sistem operasi open-source untuk perangkat mobile yang sekarang ini sedang populer, oleh karena itu android dipilih sebagai platform pengembangan Game edukasi (Borman \& Putra, 2018; Pratama \& Surahman, 2020; Sintaro et al., 2020; Suryono, 2016; Yulianto et al., 2019). Game dengan sistem android semakin banyak digemari, karna sekarang handphone bersistem android semakin banyak di pasaran dengan harga yang terjangkau oleh masyarakat umum (Borman \& Purwanto, 2019; Nurmanto \& Gunawan, 2020). Salah satu game yang dapat di kembangkan oleh sistem operasi android adalan game puzzle. Game merupakan salah satu sarana yang dapat dimanfaatkan sebagai media untuk menyampaikan berbagai jenis informasi misalnya budaya (Irvansyah et al., 2020; Syah, 2020). Menyampaikan informasi budaya dengan sebauh game diharapkan akan lebih mudah dalam mensosialisaikan buadaya tersebut pada generasi muda indonesia. Sekarang ini cara yang banyak digunakan untuk melepaskan penat dan rasa jenuh dari rutinitas sehari-hari yaitu dengan cara bermain game (Adrian, 2019; Sintaro et al., 2020), banyak orang yang menjadikan game sebagai media penghibur agar lebih santai. Game Puzzle merupakan bentuk permainan yang menantang daya kreativitas dan ingatan anak lebih mendalam dikarenakan munculnya motivasi untuk senantiasa mencoba memecahkan masalah, namun tetap menyenangkan sebab bisa di ulang-ulang.

Game atau permainan adalah sesuatu yang dapat dimainkan dengan aturan tertentu sehingga ada yang menang dan ada yang kalah, biasanya dalam konteks tidak serius atau dengan tujuan refreshing. (Dawang Muchtar, 2005). Menurut Clark C. Abt (1970), game adalah kegiatan yang melibatkan keputusan pemain, berupaya mencapai tujuan dengan "dibatasi oleh konteks tertentu" (misalnya, dibatasi oleh peraturan). Video game jenis ini sesuai namanya berintikan mengenai pemecahan teka-teki, baik itu menyusun balok, menyamakan warna bola, memecahkan perhitungan matematika, melewati labirin, sampai mendorong-dorong kota masuk ke tempat yang seharusnya, itu semua termasuk dalam jenis ini. Sering pula permainan jenis ini adalah juga unsur permainan dalam video game petualangan maupun game edukasi. Contohnya Tetris, Minesweeper, Bejeweled, Sokoban dan Bomberman.

\section{METODE PENELITIAN Populasi dan Sampel}

1. Concept (konsep)

Game edukasi puzzle rumah adat tradisional indonesia ini dibuat dengan tujuan sebagai salah satu media pembelajaran bagi siswa-siswi ataupun masyarakat untuk mengenal mengetahui jenis rumah adat tradisional yang ada di Indonesia, game puzzle ini termasuk kedalam edugame karena memuat atau membahas tentang pengetahuan rumah adat tradisional indonesia, game ini dimainkan oleh singel player atau satu pemain, game ini disajikan dalam bentuk .apk karena dimainkan dalam platform android. Pemain hanya dituntut hanya untuk merangkai dan menyusun gambar sesuai sengan gambar sebenarnya yaitu rumah adat yang ada di Indonesia (Damayanti, Akbar, et al., 2020; Yulianto et al., 2019).

\section{Design (perancangan)}

Proses selanjutnya setelah pembuatan concept dalam game kemudian dilanjutkan dengan menentukan perangkat apa yang akan digunakan untuk pembuatan game dan tampilan. Dalam tahap ini, dilakukan pembuatan spesifikasi meliputi program game edukasi puzzle rumah adat tradisional indonesia, tampilan, 
dan kebutuhan material atau bahan untuk program (Ahdan, Pambudi, et al., 2020; Damayanti, Megawaty, et al., 2020).

3. Material Collecting (pengumpulan material)

Setelah tahap concept dan design selesai dilakukan, tahap selanjutnya ialah pengumpulan material (material collecting), pada tahap ini segala hal yang dibutuhkan untuk penelitian dikumpulkan mulai dari buku, foto, audio dan lain-lain. Sehingga pada tahap ini dapat mempermudah dalam penyelesaian pembuatan game. Dalam tahapan material colecting peneliti telah mengumpulkan beberapa material yang diperlukan diantaranya ialah foto atau gambar rumah adat tradisional Indonesia (Al Irsyadi et al., 2019; Borman \& Erma, 2018).

4. Asembly (Pembuatan)

Pada tahap ini semua object atau material yang dibutuhkan sesuai konsep yang telah ditentukan pada tahap sebelumnya akan diimplementasikan kedalam project yang nantinya project tersebut menjadi sebuah aplikasi game (Ahdan, Priandika, et al., 2020; Gunawan, 2020).

5. Testing (Pengujian)

Tahapan ini sangat penting karena pada tahapan ini mempunyai fungsi utama yaitu memastikan fungsi-fungsi komponen dari sistem telah berfungsi dengan apa yang diharapkan dan sesuai dengan konsep yang telah ada (Fernando et al., 2021; Kurniawan et al., 2020).

\section{HASIL DAN PEMBAHASAN}

\section{Hasil Penelitian}

Hasil dari penelitian ini yaitu mengimplementasikan sistem agar sistem dapat dioprasikan. Setelah melakukan analisa, desain dan pengkodean menggunakan construct 2 , maka sistem yang sudah jadi akan digunakan, namun sebelum di gunakan sistem harus di lakukan testing terlebih dahulu, hal ini dimaksudkan apakah sistem berjalan dengan baik sehingga tujuan pembuatan sistem berguna

\section{Pembahasan Hasil Penelitian}

Sistem yang telah dianalisis dan didesain secara rinci dan telah diseleksi, selanjutnya sistem dapat diimplementasikan (diterapkan). Tahap implementasi sistem merupakan tahap dimana sistem siap untuk dioperasikan. Tahap ini juga termasuk dalam kegiatan melakukan pengkodean program. Berikut tampilan program yang siap diimplementasikan.

\section{Form Tampilan Loading Game}

Sebelum masuk kedalam game terdapat sebuah tampilan loading game untuk menunggu masuk kedalam game dapat dilihat pada gambar 1 berikut:

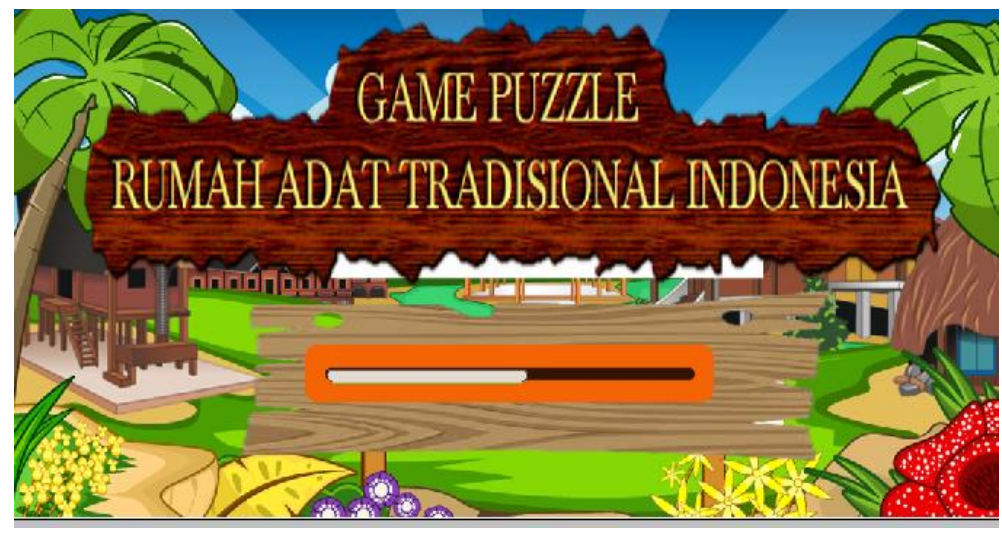

Gambar 1. Gambar Loading Game

\section{Form Tampilan Layar Materi Awal}

Sebelum masuk untuk memainkan game terdapat sebuah layar utama dimana layar ini digunakan untuk sedikit ilmu pengetahuan mengenai pahlawan, tampilan layar awal dapat dilihat pada gambar 2 berikut: 


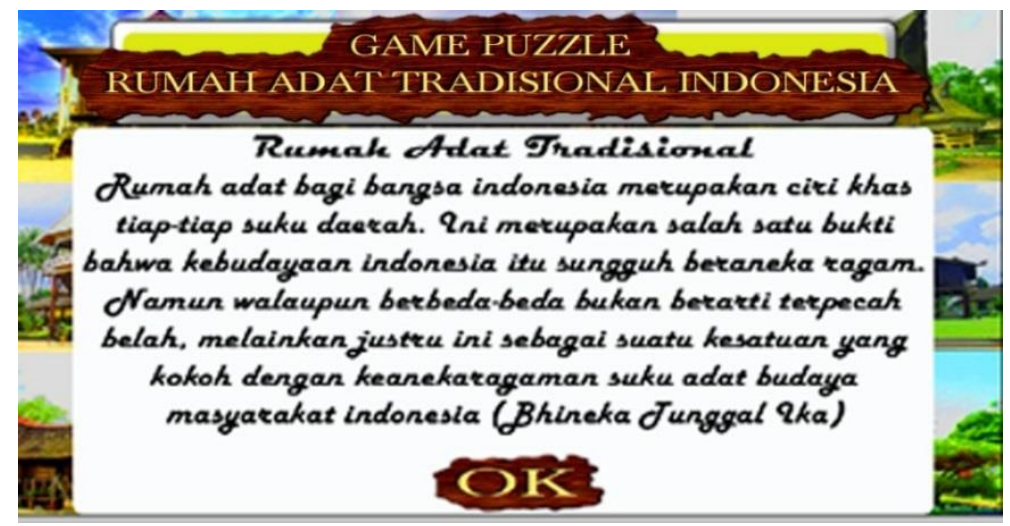

Gambar 2. Gambar Tampilan Materi Awal

\section{Form Tampilan Menu Utama}

Form menu utama adalah awal untuk memulai permainan setelah layar materi, tampilan menu utama dapat dilihat pada gambar berikut:

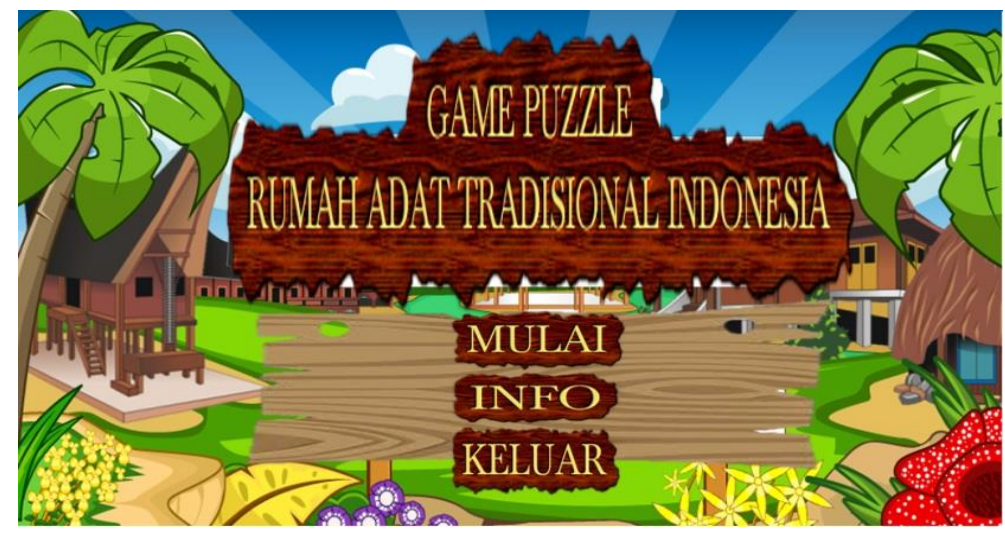

\section{Gambar 3. Gambar Menu Utama}

\section{Form Tampilan Menu Mulai}

Tampilan dalam menu mulai dapat dilihat pada gambar berikut:

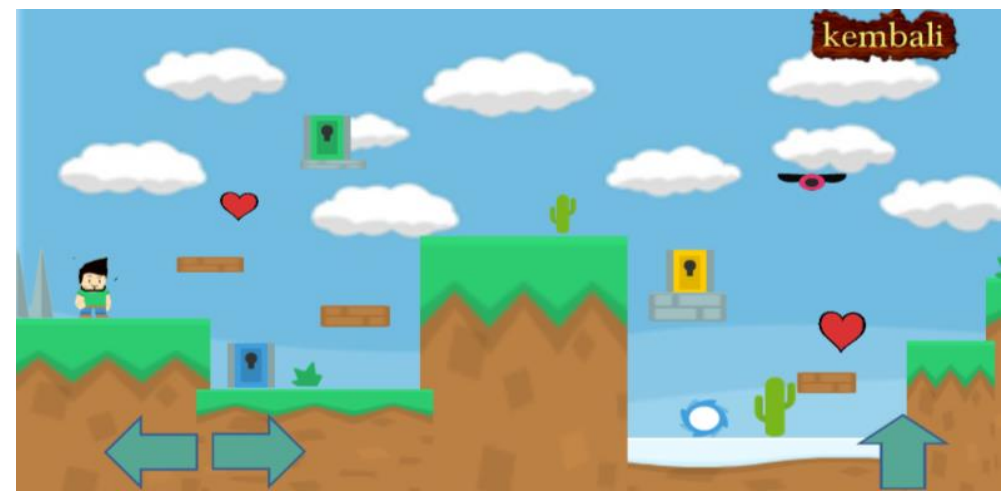

Gambar 4. Gambar Menu Mulai

Pada tampilan menu mulai pemain akan ditujukan pada permainan petualanagan dimana terdapat rintangan yang harus di lalui dan harus mengambil poin agar dapat melanjutkan ke game puzzle.

Form Tampilan Menu Info

Dari gambar terdapat gambar info dari game puzzle rumah adat tradisional indonesia. 


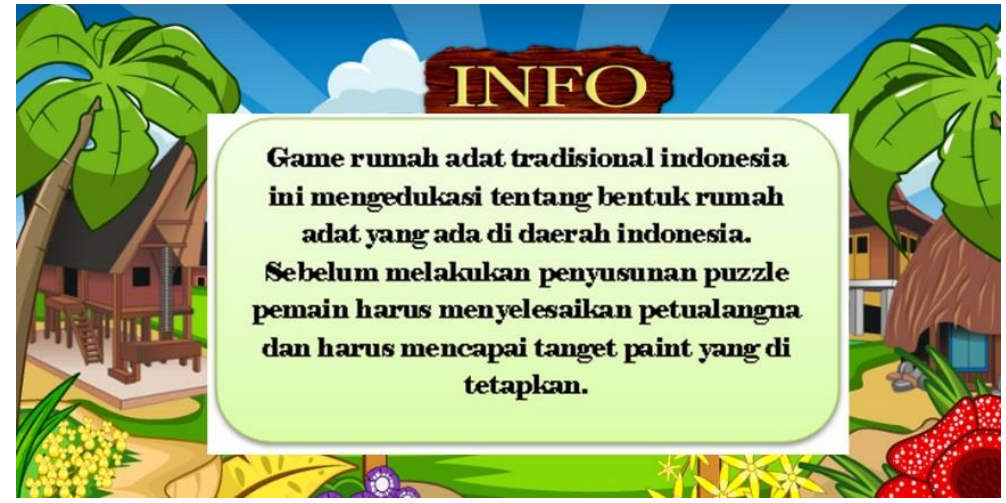

Gambar 5. Gambar Menu Info

Form Tampilan Menu Pilih Daerah

Dari gambar terdapat gambar rumah adat dari daerah yang ada di indonesia.

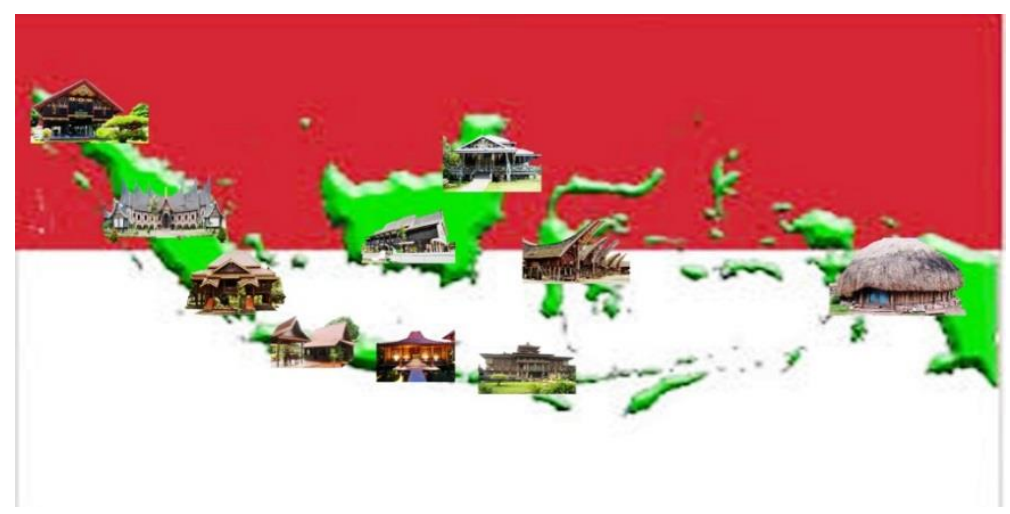

Gambar 6. Gambar menu Pilih Daerah

\section{Form Tampilan Menu Game Puzzle}

Dari gambar terdapat gambar rumah adat sebelum di pecah dan di acak.

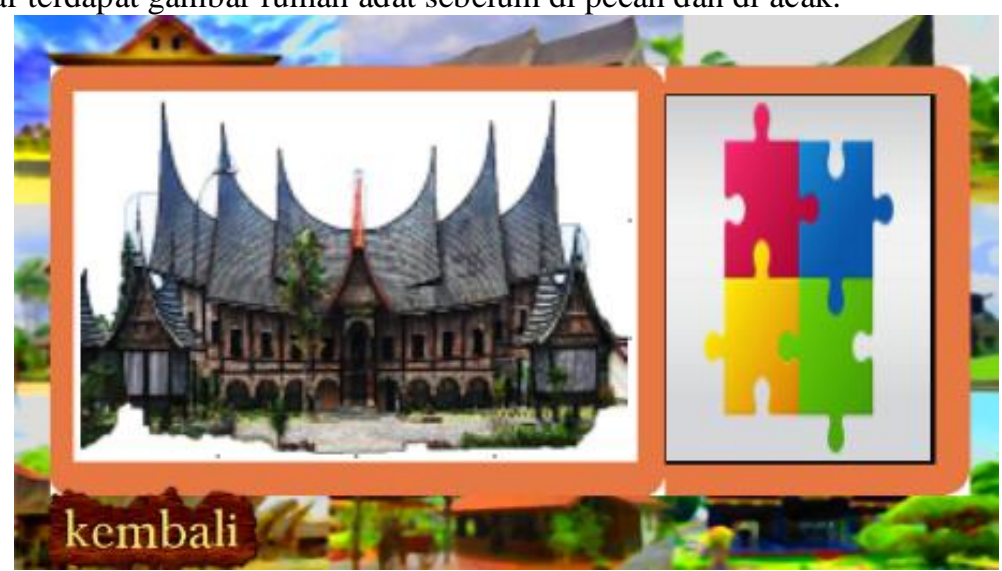

Gambar 7. Gambar Game Puzzle

Selanjutnya adalah tampilan menu game Puzzle dapat dilihat pada gambar berikut: 


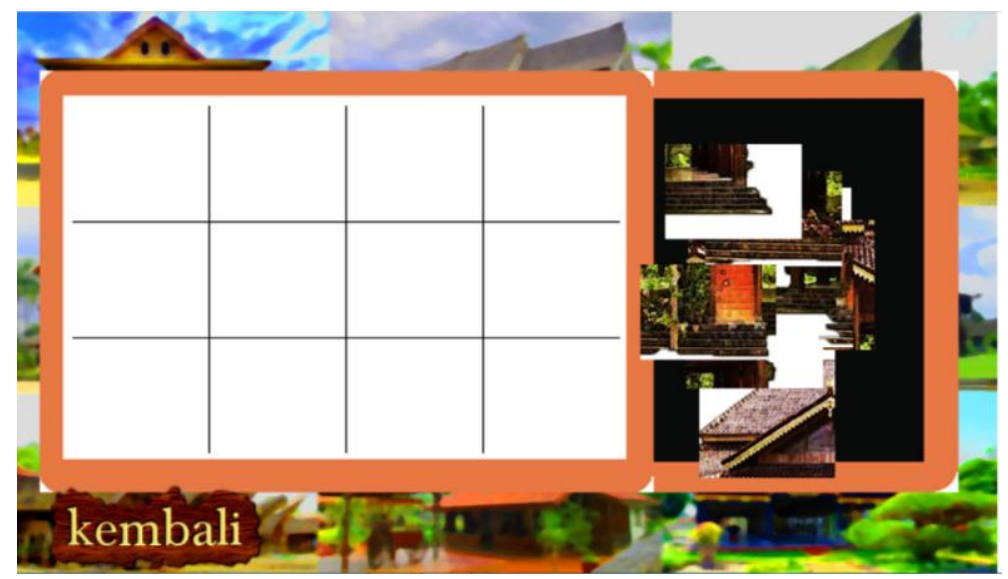

Gambar 8. Gambar Susun Game Puzzle

\section{Form Tampilan Menu Edukasi Rumah Adat} berikut:

Dan yang selanjutnya ialah form tampilan menu penjelasan tentang rumah adat dapat dilihat pada gambar

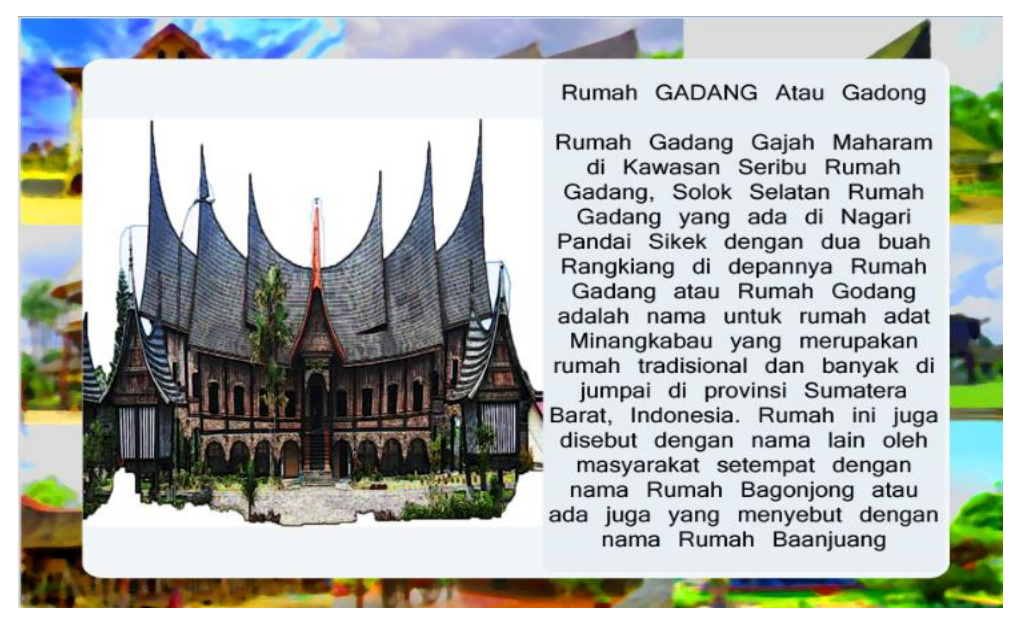

Gambar 9. Gambar Menu Edukasi Rumah Adat

\section{SIMPULAN}

Berdasarkan hasil dari penelitian maka dapat dihasilkan simpulan sebagai berikut Berdasarkan penelitian yang sudah dilakukan dapat disimpulkan bahwa Game Edukasi Puzzle Rumah Adat Tradisional Indonesia dapat mengenalkan rumah adat yang ada di Indonesia. Berdasarkan hasil kuisioner pada tabel 4.4 tentang seberapa mengedukasi game edukasi puzzle rumah adat tradisional indonesia, sebanyak 10 responden atau 50\% mengatakan sangat setuju dan berdasarkan hasil kuisioner pada tabel 4.9 sebanyak 13 responden atau $65 \%$ sangat setuju, sehingga dapat disimpulkan bahwa game edukasi puzzzle rumah adat tradisional indonesia dapat menambah pengetahuan anak-anak tentang rumah adat yang ada di indonesia.

\section{REFERENSI/DAFTAR PUSTAKA}

Adrian, Q. J. (2019). Game Edukasi Pembelajaran Matematika untuk Anak SD Kelas 1 dan 2 Berbasis Android. Jurnal Teknoinfo, 13(1), 51-54.

Ahdan, S., Pambudi, T., Sucipto, A., \& Nurhada, Y. A. (2020). Game Untuk Menstimulasi Kecerdasan Majemuk Pada Anak 
(Multiple Intelligence) Berbasis Android. Prosiding-Seminar Nasional Teknik Elektro UIN Sunan Gunung Djati Bandung, 554-568.

Ahdan, S., Priandika, A. T., Andhika, F., \& Amalia, F. S. (2020). PERANCANGAN MEDIA PEMBELAJARAN TEKNIK DASAR BOLA VOLI MENGUNAKAN TEKNOLOGI AUGMENTED REALITY BERBASIS ANDROID LEARNING MEDIA FOR BASIC TECHNIQUES OF VOLLEYBALL USING ANDROID-BASED AUGMENTED REALITY TECHNOLOGY.

Al Irsyadi, F. Y., Puspitassari, D., \& Kurniawan, Y. I. (2019). AB AS (Ayo Belajar Sholat) : Game Edukasi Pembelajaran Sholat Untuk Anak Tuna Rungu Wicara. Jurnal Manajemen Informatika (JAMIKA), 9(1), 17-28. https://doi.org/10.34010/jamika.v9i1.1537

Borman, R. I., \& Erma, I. (2018). Pengembangan Game Edukasi Untuk Anak Taman Kanak-Kanak (TK) Dengan Implementasi Model Pembelajaran Visualitation Auditory Kinestethic (VAK). JIPI (Jurnal Ilmiah Penelitian Dan Pembelajaran Informatika), 3(1).

Borman, R. I., \& Purwanto, Y. (2019). Impelementasi Multimedia Development Life Cycle pada Pengembangan Game Edukasi Pengenalan Bahaya Sampah pada Anak. JEPIN (Jurnal Edukasi Dan Penelitian Informatika), 5(2), 119-124.

Borman, R. I., \& Putra, A. S. (2018). Game Pengenalan Huruf Hijaiyah Untuk Anak Autis Dengan Penerpan Pendekatan Edukasi Multisensori. SEMNASTEKNOMEDIA ONLINE, 6(1), 1-6.

Damayanti, D., Akbar, M. F., \& Sulistiani, H. (2020). Game Edukasi Pengenalan Hewan Langka Berbasis Android Menggunakan Construct 2. Jurnal Teknologi Informasi Dan Ilmu Komputer, 7(2), 275-282.

Damayanti, D., Megawaty, D. A., Rio, M. G., Rubiyah, R., Yanto, R., \& Nurwanti, I. (2020). Analisis Interaksi Sosial Terhadap Pengalaman Pengguna Untuk Loyalitas Dalam Bermain Game. JSI: Jurnal Sistem Informasi (E-Journal), 12(2).

Fernando, Y., Ahmad, I., Azmi, A., \& Borman, R. I. (2021). Penerapan Teknologi Augmented Reality Katalog Perumahan Sebagai Media Pemasaran Pada PT. San Esha Arthamas. J-SAKTI (Jurnal Sains Komputer Dan Informatika), 5(1), 6271.

Gunawan, R. D. (2020). PEMANFAATAN AUGMENTED REALITY DALAM APLIKASI MAGIC BOOK PENGENALAN PROFESI UNTUK PENDIDIKAN ANAK USIA DINI. Jurnal Informatika Dan Rekayasa Perangkat Lunak, 1(1), 3642.

Irvansyah, F., Muhaqiqin, \& Setiawansyah. (2020). Aplikasi pemesanan jasa cukur rambut berbasis android. 1(1), $26-32$.

Kurniawan, I., Setiawansyah, \& Nuralia. (2020). PEMANFAATAN TEKNOLOGI AUGMENTED REALITY UNTUK PENGENALAN PAHLAWAN INDONESIA DENGAN MARKER. Jurnal Informatika Dan Rekayasa Perangkat Lunak, 1(1), 9-16.

Nurmanto, D., \& Gunawan, R. D. (2020). PEMANFAATAN AUGMENTED REALITY DALAM APLIKASI MAGIC BOOK PENGENALAN PROFESI UNTUK PENDIDIKAN ANAK USIA DINI. 1(1), 36-42.

Pratama, R. R., \& Surahman, A. (2020). PERANCANGAN APLIKASI GAME FIGHTING 2 DIMENSI DENGAN TEMA KARAKTER NUSANTARA BERBASIS ANDROID MENGGUNAKAN CONSTRUCT 2. Jurnal Informatika Dan Rekayasa Perangkat Lunak, 1(2), 234-244.

Sintaro, S., Ramdani, R., \& Samsugi, S. (2020). Rancang Bangun Game Edukasi Tempat Bersejarah Di. 1(1), 51-57.

Suryono, R. R. (2016). Perilaku Pemain Game Online terhadap Pembelian Virtual Item. Institut Teknologi Sepuluh Nopember.

Syah, S. (2020). PEMANFAATAN TEKNOLOGI AUGMENTED REALITYUNTUK PENGENALAN PAHLAWAN INDONESIA DENGAN MARKER UANG KERTAS INDONESIA. Jurnal Informatika Dan Rekayasa Perangkat Lunak, 1(1), 9-16.

Yulianto, F., Utami, Y. T., \& Ahmad, I. (2019). Game Edukasi Pengenalan Buah-buahan Bervitamin C untuk Anak Usia Dini. Jurnal Nasional Pendidikan Teknik Informatika: JANAPATI, 7(3), 242-251. 